\title{
A Double-Blind Randomized Placebo-Controlled Trial of Oral Naltrexone for Heavy-Drinking Smokers Seeking Smoking Cessation Treatment
}

\author{
Christopher W. Kahler (ID, Patricia A. Cioe, Golfo K. Tzilos, Nichea S. Spillane, \\ Lorenzo Leggio (D), Susan E. Ramsey, Richard A. Brown, and Stephanie S. O'Malley
}

\begin{abstract}
Background: Post hoc analyses of 2 randomized controlled trials suggest naltrexone may reduce alcohol use and improve smoking cessation outcomes among heavy drinkers receiving smoking cessation treatment. However, no studies have been conducted specifically to examine naltrexone for this purpose or to test whether naltrexone has benefit when added to smoking cessation counseling that explicitly addresses heavy drinking.

Methods: We recruited heavy-drinking smokers from the community and randomized them to receive 10 weeks of either (i) $50 \mathrm{mg}$ naltrexone $(n=75)$ or (ii) placebo $(n=75)$ daily. Participants received 6 weeks of transdermal nicotine patch and 6 sessions of counseling that addressed both heavy drinking and smoking. Participants were followed for 26 weeks after their target quit smoking date.

Results: Across medication conditions, there were substantial reductions at follow-up in percent heavy drinking days (primary outcome) and average drinks per week (secondary outcome). However, participants receiving naltrexone did not differ significantly from those receiving placebo on percent heavy drinking days (effect size $d=-0.04,95 \%$ CI $[-0.30,0.22], p=0.76$ ) or average drinks per week $(d=-0.09,95 \%$ CI $[-0.35,0.18], p=0.54)$ during follow-up. Naltrexone compared to placebo was not associated with a significant increase in smoking abstinence rates during follow-up, odds ratio $=0.93,95 \% \mathrm{CI}[0.46,1.86], p=0.83$. The effect of naltrexone on these outcomes was not significantly moderated by current alcohol dependence or gender.

Conclusions: Results indicate that heavy-drinking smokers, including those with current alcohol dependence, can make substantial reductions in drinking in the context of smoking cessation treatment. However, this study provided no evidence that naltrexone is efficacious for enhancing reductions in drinking or improving smoking cessation in this population. Limitations of this study included lowerthan-desired sample size and modest adherence to study medication.
\end{abstract}

Key Words: Naltrexone, Heavy Drinking, Alcohol Dependence, Smoking Cessation.

From the Department of Behavioral and Social Sciences (CWK, $P A C, L L)$, Center for Alcohol and Addiction Studies, Brown University School of Public Health, Providence, Rhode Island; Department of Family Medicine (GKT), University of Michigan, Ann Arbor, Michigan; Department of Psychology (NSS), University of Rhode Island, South Kingston, Rhode Island; Section on Clinical Psychoneuroendocrinology and Neuropsychopharmacology (LL), National Institute on Alcohol Abuse and Alcoholism and National Institute on Drug Abuse, Bethesda, Maryland; Department of Psychiatry and Human Behavior (SER), The Warren Alpert Medical School of Brown University and Rhode Island Hospital, Providence, Rhode Island; Department of Medicine (SER), The Warren Alpert Medical School of Brown University and Rhode Island Hospital, Providence, Rhode Island; University of Texas at Austin (RAB), Austin, Texas; and Department of Psychiatry (SSO), Yale School of Medicine, New Haven, Connecticut.

Received for publication October 31, 2016; accepted April 6, 2017.

Reprint requests: Christopher W. Kahler, PhD, Department of Behavioral and Social Sciences, Center for Alcohol and Addiction Studies, Brown University School of Public Health, Box G-S121-4, Providence, RI 02912; Tel.: 401-863-6651; Fax: 401-863-6697; E-mail: Christopher_ Kahler@brown.edu

Copyright $(2017$ by the Research Society on Alcoholism.

DOI: 10.1111/acer.13396
REATER ALCOHOL USE is positively associated Jith smoking initiation and escalation to regular cigarette use and dependence (Kahler et al., 2009). Smokers are more than twice as likely as nonsmokers to be hazardous drinkers (McKee et al., 2007), and combined heavy alcohol use and smoking inflict significant harmful health effects (Ebbert et al., 2005; Meyerhoff et al., 2006; Schroder et al., 2002). Alcohol use is among the most common smoking relapse precipitants (Baer and Lichtenstein, 1988; Borland, 1990; Shiffman et al., 1996). Heavy drinkers report that over $40 \%$ of their first smoking lapses during a quit attempt occurred when they were drinking alcohol (Kahler et al., 2010). In observational (Augustson et al., 2008; Dollar et al., 2009; Kahler et al., 2009) and clinical studies (Cook et al., 2012; Humfleet et al., 1999; Smith et al., 1999; Toll et al., 2012), greater alcohol use has been associated with a reduced odds of smoking cessation with episodic heavy drinking (4+ drinks/d in women; 5+ drinks/d in men) being the most robust predictor of poor smoking outcomes (Cook et al., 2012; Kahler et al., 2009; Leeman et al., 2008; Murray et al., 
1995). Therefore, addressing heavy alcohol use in smokers who are making a quit smoking attempt is a pressing public health priority.

In the first trial of its kind, Kahler and colleagues (2008) tested the efficacy of a smoking cessation treatment targeted to non-alcohol-dependent heavy drinkers that incorporated a brief intervention to motivate reductions in alcohol consumption. Results showed promise for this approach in reducing alcohol consumption over 6 months, but positive effects on smoking cessation tended to fade over time. This lack of sustained effect on smoking cessation was primarily due to a lack of impact among the heaviest drinkers in the sample. In a subsequent study, Toll and colleagues (2015) incorporated brief intervention to reduce alcohol use in heavy drinkers calling a state smoking quitline. Alcohol-focused counseling for smoking cessation was significantly more effective in promoting smoking cessation at 7 months postcounseling compared to standard quitline counseling. A trend toward reduced prevalence of heavy drinking in the alcohol-focused versus standard counseling was also observed. These studies highlight the potential value of combined interventions that simultaneously address smoking and alcohol use among heavy drinkers seeking smoking cessation treatment.

An intriguing possibility for enhancing alcohol use reductions and smoking cessation in heavy-drinking smokers is combining effective smoking cessation pharmacotherapies with pharmacotherapies that impact alcohol use (Yardley et al., 2015). In this study, we focused on naltrexone, an opiate antagonist that is Food and Drug Administration (FDA)approved for alcohol use disorder treatment and has been shown to reduce heavy drinking in non-abstinence-oriented alcohol treatments (Kranzler et al., 2003; Morgenstern et al., 2012; O'Malley et al., 2015). Although some laboratory studies (Epstein and King, 2004; King and Meyer, 2000; Rohsenow et al., 2007; Rukstalis et al., 2005) but not others (Epstein and King, 2004; Rohsenow et al., 2007; Sutherland et al., 1995) have suggested that naltrexone may reduce craving and the reinforcing value of cigarettes, its efficacy as a smoking cessation pharmacotherapy has not been supported (Hartmann-Boyce et al., 2014). One recent exception demonstrated short-term efficacy for smoking cessation when naltrexone was combined with bupropion (Mooney et al., 2016).

There is some evidence from a human laboratory study that naltrexone may reduce the effect of alcohol use on cigarette craving in nontreatment seeking heavy-drinking light smokers (Ray et al., 2007), which suggests that naltrexone could protect against lapses to smoking that occur when recently quit smokers are drinking. This hypothesis has not been evaluated in a treatment-oriented clinical trial. However, 2 randomized clinical trials that evaluated naltrexone versus placebo combined with nicotine patch for smoking cessation have conducted post hoc analyses to determine whether naltrexone had beneficial effects on alcohol use and smoking outcomes in participants who were heavy drinkers. One study found that 12 weeks of naltrexone $50 \mathrm{mg} / \mathrm{d}$ compared to placebo increased smoking abstinence and reduced alcohol use during treatment in heavy-drinking participants but not in moderate-to-light drinkers or nondrinkers (Fridberg et al., 2014). A second study compared 6 weeks of 25 , 50 , and $100 \mathrm{mg}$ of naltrexone daily to placebo, and found that both 25 and $50 \mathrm{mg}$ naltrexone decreased alcohol use relative to placebo; however, there was no benefit for smoking cessation (O'Malley et al., 2009). Thus, there is (i) evidence that naltrexone may reduce heavy drinking in the context of smoking cessation and (ii) mixed evidence that naltrexone may promote smoking cessation in the subset of smokers who drink heavily. No published studies to date have been designed a priori to test the effects of naltrexone among heavy-drinking smokers, nor have any studies tested naltrexone in the context of counseling that addresses both smoking cessation and heavy drinking. Therefore, the utility of naltrexone for heavy drinkers seeking smoking cessation treatment remains unclear.

\section{Study Aims}

The purpose of this study was to test the efficacy of a 10week course of $50 \mathrm{mg} / \mathrm{d}$ of naltrexone on alcohol use and smoking outcomes among heavy drinkers seeking smoking cessation treatment. As in the Fridberg and colleagues (2014) and O'Malley and colleagues (2009) studies, participants received transdermal nicotine patch starting on their target quit smoking date. Unlike those studies, we did not exclude participants who met criteria for DSM-IV alcohol dependence (American Psychiatric Association, 1994), and all participants received counseling that addressed both alcohol and smoking.

We hypothesized that naltrexone, compared to placebo, would result in greater reductions in frequency of heavy drinking days during treatment and in the 4 months after treatment. We further hypothesized that naltrexone would (i) reduce the odds of having an alcohol-involved smoking lapse during treatment, and (ii) increase the odds of smoking abstinence at 2, 8, 16, and 26 weeks after participants' target quit smoking date. Smoking abstinence was considered a secondary outcome given the mixed evidence of the efficacy of naltrexone for that outcome. In addition, we tested the hypothesis that naltrexone's effects would be moderated by alcohol dependence, such that its efficacy for reducing drinking and enhancing smoking cessation would be most evident in those with current alcohol dependence. We also tested whether gender moderated naltrexone's effects given mixed evidence regarding whether women or men benefit differently from naltrexone for alcohol dependence (Garbutt et al., 2014) and smoking cessation (Epperson et al., 2010; King et al., 2012).

\section{MATERIALS AND METHODS}

\section{Study Design}

We utilized a randomized double-blind, placebo-controlled trial to test the efficacy of 10 weeks of naltrexone $50 \mathrm{mg} / \mathrm{d}$ for decreasing heavy drinking and increasing smoking abstinence among heavy 
drinkers seeking smoking cessation treatment. All participants received 6 weeks of treatment with transdermal nicotine patch and 6 sessions of counseling that focused on smoking cessation, alcohol reduction, and utilization of study medication. Outcomes were assessed through 26 weeks after participants' target quit smoking dates. The study was approved by the Brown University and Lifespan Hospitals Institutional Review Boards (ClinicalTrials.gov: NCT00938886).

Sample Size and Power. We set desired sample size to detect a small to medium effect of naltrexone $(d=0.30)$ on percent heavy drinking days with power of 0.80 and $\alpha=0.05$, assuming 3 followup assessments and correlations among those repeated measures that mirrored our prior study (Kahler et al., 2008). Required sample size was estimated at 134 participants per condition. Allowing for attrition from follow-up of about $10 \%$, we sought to recruit a total sample of 300 . However, due to persistent difficulties in recruiting participants, we were only able to randomize 150 total participants, of whom 133 completed 26-week follow-up; the reduced sample size meant that we had power of 0.80 to detect an effect size $d$ of 0.43 , but only power of 0.50 to detect a $d$ of 0.30 .

\section{Participants}

Participants were recruited from Providence, RI, and the surrounding community through bulletin board, radio, Internet, newspaper, and public transportation advertisements. Additionally, we posted flyers in physicians' offices and recruited directly from university-affiliated primary care clinics. To be included, participants had to (i) be $\geq 18$ years old; (ii) have smoked cigarettes regularly for at least 1 year; (iii) currently smoke $\geq 5$ cigarettes a day; (iv) currently use no other tobacco products or nicotine replacement therapy; and (v) currently report drinking heavily at least once per month on average $(\geq 4$ drinks per occasion for women; $\geq 5$ drinks for men). Participants were excluded if they (i) met DSM-IV criteria for substance dependence (excluding nicotine and alcohol) in the past 12 months; (ii) reported opioid use in the past month, had a drug screen positive for opioids, or required opioid medication for pain management; (iii) met criteria for a current major depressive or manic episode; (iv) had current psychotic symptoms; (v) had an unstable or serious medical condition that would preclude use of nicotine patch or naltrexone; (vi) had aspartate aminotransferase or alanine aminotransferase levels more than 3 times the reference range, or clinically elevated bilirubin levels; or (vii) were currently pregnant or lactating, intended to become pregnant, or were not using a reliable method of birth control. We excluded participants with a history of severe alcohol withdrawal and those currently receiving treatment for a primary alcohol problem.

\section{Study Procedure}

Potential participants were screened by telephone before completing an intake interview, at which they signed informed consent. Participants were recruited from October 2009 through April 2015, and follow-ups were conducted from January 2010 through October 2015. Figure 1 provides the CONSORT diagram of participant flow.

\section{Baseline Assessment and Physical Examination}

The baseline interview assessed demographic information; alcohol, tobacco, and other drug use; and vital signs. A breath alcohol level was taken, and those with a detectable breath alcohol concentration (BrAC) were rescheduled. Participants provided blood and urine specimens for pregnancy and laboratory testing. The study medical provider made final eligibility determination based on these results and physical examination findings.

\section{Randomization}

Eligible participants were assigned to medication condition by a staff member uninvolved in assessment using computerized urn randomization (Wei, 1978), to ensure balance on gender, score on the Fagerström Test for Nicotine Dependence (FTND; Heatherton et al., 1991), drinks consumed per week, and intention to change drinking while quitting smoking. Seventy-five participants were randomized to placebo and 75 to naltrexone. The study medical provider dispensed blinded study medications at the conclusion of the physical examination.

\section{Counseling and Medication Management}

Counseling and medication management (CMM) comprised 6 individual counseling sessions over a 9-week period with quit date occurring at session 2. Following physical examination, eligible participants were scheduled for a counseling session during the following week. Counseling was delivered by 6 female counselors with prior experience in nursing or counseling ( 3 were bachelor's-level nurses, 1 held a master's degree, and 2 held doctoral degrees). Counselors used detailed manuals to ensure standardization of treatment delivery. They completed approximately 20 hours of training in motivational interviewing (Miller and Rollnick, 2012) and smoking cessation counseling, including assigned readings and group didactic sessions. They discussed each case at a weekly group supervision meeting led by a licensed clinical psychologist (CWK). All sessions were audio-recorded for supervision purposes.

The CMM intervention provided (i) smoking cessation treatment consistent with clinical practice guidelines (Brown et al., 2014; Fiore et al., 2008; Kahler et al., 2008), (ii) counseling on alcohol and its impact on smoking cessation (Kahler et al., 2008), and (iii) monitoring of oral study medication use and safety following guidelines in medical management (Pettinati et al., 2004). Session 1 occurred 1 week after physical examination and initiation of study medication. It focused on preparation for quitting smoking, identifying high-risk situations, enlisting social support, and developing coping strategies. Normative feedback was provided on drinking and risk of smoking relapse associated with drinking. The role of alcohol use in smoking relapse served as an entry into discussion of possible short- and long-term changes in drinking. This session included monitoring of naltrexone adherence, as well as provision of nicotine patch and instruction in its use. Session 2 occurred the following week and coincided with participants' target quit smoking date, with sessions 3 to 6 occurring 1, 2, 4, and 8 weeks after quit date, respectively. These sessions focused on study medication use, side effects, progress in quitting smoking, provision of support, review of current drinking, efforts to modify drinking, and problem solving for high-risk situations for smoking relapse. Session 1 lasted approximately 40 minutes with remaining sessions lasting $20 \mathrm{~min}$ utes. A BrAC was taken on participants before each session, and sessions were rescheduled if $\mathrm{BrAC}$ was over 0.02 , which occurred at less than $1 \%$ of sessions.

\section{Pharmacotherapy}

Participants were instructed to take their first dose of study oral medication at the conclusion of the physical examination (2 weeks before the target quit smoking date) and to take 1 tablet daily for 10 weeks. The first titration doses of 12.5 and $25 \mathrm{mg}$ were packed by the pharmacist in individual glassine envelopes and placed within the medication bottle. Those assigned to placebo received pills that were indistinguishable from active medication. Medication bottles were fitted with child-resistant MEMS $^{\circledR} 6$ TrackCaps from AARDEX Ltd. (Sion, Switzerland), which electronically recorded dates and times of bottle openings. All participants were told there was a 50 to 50 chance of receiving naltrexone or placebo and that neither 


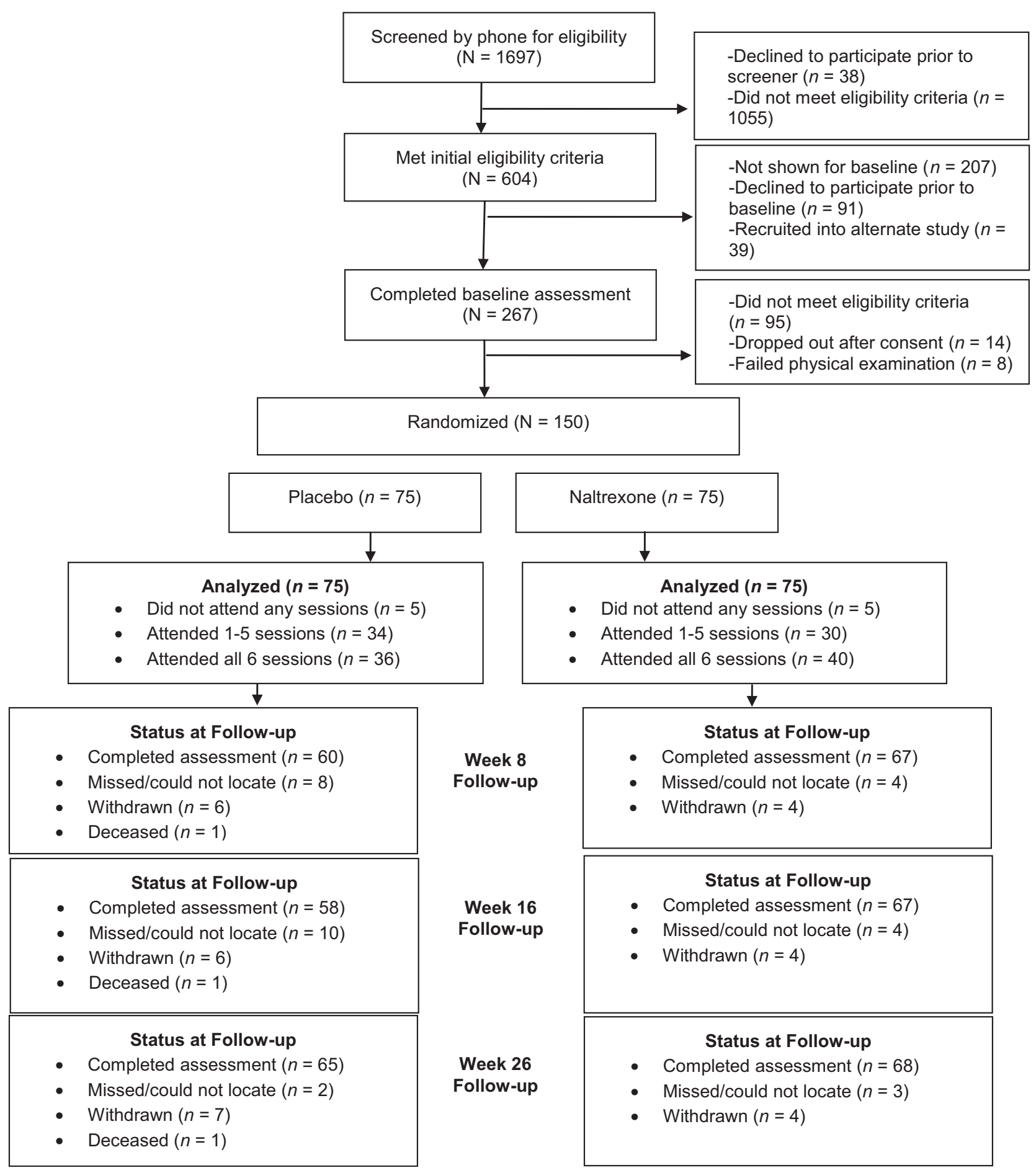

Fig. 1. CONSORT diagram showing participant flow.

they nor their treatment providers would be informed which medication they received. Participants were instructed to bring their medication bottle to each visit for pill counts and downloading of TrackCap data.

All participants received a 6-week course of transdermal nicotine patch: $21 \mathrm{mg}$ for 2 weeks (14 mg for those smoking 5 to 10 cigarettes per day) followed by $14 \mathrm{mg}$ for 2 weeks and then $7 \mathrm{mg}$ for 2 weeks. Participants were instructed to apply the patch immediately upon waking on their quit date and to apply 1 patch daily thereafter. Participants were informed of the efficacy of nicotine patch for smoking cessation, and adherence was strongly encouraged.

\section{Assessments}

Participants completed assessments at baseline and each counseling session. In addition, follow-ups were conducted at 8, 16, and 26 weeks after participants' quit date. Research assistants who 
conducted interviews were not informed of medication assignment. Multiple methods were used to maximize retention in follow-ups including payments $(\$ 30, \$ 30$, and $\$ 50$, at 8,16 , and 26 weeks, respectively), phone and letter reminders about follow-up appointments, and use of collateral informants to gather contact information on participants lost to follow-up.

Structured Clinical Interview for DSM-IV. Diagnostic exclusions and lifetime prevalence of key Axis I diagnoses were determined at baseline by the substance use and affective disorders sections of the Structured Clinical Interview for DSM-IV (SCID), nonpatient version (First et al., 1995). The SCID was administered by trained interviewers and supervised by licensed psychologists who regularly reviewed audiotaped interviews.

Medical Screening and Vital Signs. At baseline, participants completed a medical screen focused on contraindications for using nicotine patch and naltrexone. Vital signs were also taken at baseline and each assessment. Participants completed a urine drug screen and provided a blood sample for liver function testing. At baseline, the Clinical Institute Withdrawal Assessment for Alcohol-Revised (CIWA-Ar; Sullivan et al., 1989) was administered to determine whether overnight abstinence from alcohol led to clinically significant alcohol withdrawal symptoms.

Alcohol Use and Withdrawal. The Timeline Follow-Back Interview (TLFB; Sobell and Sobell, 1996), a well-validated calendarassisted interview, was used at baseline to assess alcohol use in the prior 8 weeks. TLFB was conducted at each counseling session, and at 8-, 16-, and 26-week follow-ups to assess alcohol use since last study visit. From the TLFB, we calculated 2 outcome variables: percent heavy drinking days (primary alcohol use outcome) and average drinks per week (secondary alcohol use outcome). Alcohol withdrawal symptoms were assessed by the Short Alcohol Withdrawal Scale (Gossop et al., 2002) and the CIWA-Ar at all treatment sessions; no participants required medical detoxification.

Cigarette Smoking and Nicotine Dependence. The FTND provided a continuous measure of nicotine dependence, and the TLFB assessed number of cigarettes smoked per day (Brown et al., 1998). Smoking data were collected with the TLFB at each counseling session and at all follow-ups. A relapse interview (Kahler et al., 2010) was administered to participants who lapsed to smoking after quit date to determine the circumstances surrounding the initial lapse episode, including whether individuals were drinking alcohol.

Our primary smoking outcome was biochemically verified 7-day point-prevalence smoking abstinence at 2, 8, 16, and 26 weeks after quit date. Self-reported abstinence was verified at all assessments using carbon monoxide (CO) analysis of breath samples with a 4 ppm cutoff (Cropsey et al., 2014), and at 8, 16, and 26 weeks, it was also verified using saliva cotinine (cutoff value of $15 \mathrm{ng} / \mathrm{ml}$ ) (SRNT Subcommittee on Biochemical Verification, 2002) as determined by enzyme immunoassay. Abstinence was verified by having both $\mathrm{CO}$ and cotinine levels under the stated cutoffs. For those who reported using nicotine replacement at the 8-, 16-, and 26-week follow-ups, we relied only on $\mathrm{CO}$ for biochemical verification. For those who were unable to come to the study center, we confirmed smoking abstinence by calling a collateral informant whose contact information was provided by the participant at baseline. Only individuals who had smoking abstinence confirmed at a given follow-up were considered abstinent; those with missing data were considered nonabstinent. We also ran analyses in which no assumptions were made about missing data; results using no missingness assumptions were highly concordant with those using a "worst-case" assumption and are therefore not detailed here. Our secondary smoking outcome was continuous smoking abstinence, defined as reporting no smoking from 2 to 26 weeks after quit date (Hughes et al., 2003) and being verified abstinent at each follow-up. We also categorized participants as continuously abstinent or not during active treatment.

Medication Side Effects and Adherence. At each treatment session, a side effects checklist was completed based on the Systematic Assessment For Treatment Emergent Events (SAFTEE) (Levine and Schooler, 1986; Pettinati et al., 2004), which was modified to assess the most common side effects of naltrexone and nicotine patch. Participants were asked whether they experienced each symptom since their previous study visit, and the counselor rated the symptom as minimal, mild, moderate, or severe based on protocol guidelines.

Adherence to oral study medication was assessed by self-report, pill count, and MEMS $^{\circledR} 6$ TrackCaps. Pills taken and nicotine patch use were recorded for each day using the TLFB. TrackCaps data were downloaded and pill counts conducted at each treatment session.

\section{Data Analysis Plan}

We examined demographic and clinical characteristics in the sample as a whole and within each treatment condition. We next examined session attendance, nicotine patch use, oral medication adherence, and occurrence of adverse events. We used $t$-tests and chi-square tests to determine whether there were significant between-condition differences on these variables.

Alcohol Outcomes. We examined primary (percent heavy drinking days) and secondary (average drinks per week) alcohol use outcomes during weeks 3 to 10 on medication (corresponding to weeks 1 to 8 after target quit smoking date), during weeks 9 to 16 after quit date (when no longer on medication), and during weeks 17 to 26 after quit date; these variables were log-transformed to correct positive skewness and standardized so that model coefficients could be interpreted as effect size $d$. To examine the effect of treatment (dummy coded with placebo as the reference group) within the context of other covariates, repeated-measures analyses were conducted using generalized estimating equations (GEE) (Zeger and Liang, 1986) using PROC GENMOD in SAS (SAS Institute Inc., 2012); GEE is particularly robust to model misspecification and well-suited for addressing marginal (i.e., between groups) effects. Analyses controlled for factors in the urn randomization (gender, FTND, drinks per week, and the linear effect of intention to change drinking). A linear effect of time (centered) and a time by group interaction were included to test whether naltrexone effects became weaker once treatment was completed. In a second step, we added alcohol dependence and the naltrexone by alcohol dependence interaction to test whether naltrexone effects were stronger among those with current alcohol dependence and also added the interaction between naltrexone and gender. Analyses included all 136 participants $(90.7 \%$ of the sample) who provided any follow-up data on alcohol use. The proportion of participants providing alcohol follow-up data did not differ by medication condition $(88.0 \%$ in placebo vs. $93.3 \%$ in naltrexone, $\left.\chi^{2}=1.26, \quad p=0.26\right)$. As a supplemental approach to examine the effect of naltrexone under relatively high rates of medication adherence, analyses for alcohol and smoking outcomes were repeated including only participants who took at least two-thirds of medication doses across all adherence measures $(n=72)$. For both alcohol and smoking outcomes, we examined whether including counselor as a term in GEE models improved model fit or altered conclusions and found it did not.

Smoking Outcomes. We ran logistic regression analyses with the a priori covariates to predict the odds of having an alcohol-involved lapse to smoking during treatment. We then used GEE with a 
binomial distribution and logit link function to analyze the odds of smoking abstinence at 2, 8, 16, and 26 weeks after quit date. A linear effect of time (centered) and a time by group interaction were also included. We then added naltrexone by alcohol dependence and naltrexone by gender interactions to the model. We used logistic regression to test whether naltrexone was associated with greater odds of continuous smoking abstinence during active treatment and over the course of the study.

\section{RESULTS}

\section{Baseline Characteristics}

Sample characteristics are shown in Table 1. For all variables examined, conditions did not differ significantly.

\section{Treatment Exposure and Adverse Events}

Table 2 shows session attendance, nicotine patch use, and medication adherence. Percent of medication doses taken did not differ significantly by condition whether estimated by self-report, pill count, or bottle openings. For both nicotine patch and oral medication, participants self-reported using about three-quarters of the medications they were given. Oral medication adherence estimated by vial openings was substantially lower than both self-report and pill count estimates.
Adverse effects to study medications of any degree (minimal, mild, moderate, severe) were reported by $126(84.0 \%)$ of participants, and the most common were insomnia, fatigue, and anxiety/nervousness. There were no differences on the overall frequency of adverse effects of any degree by medication condition $\left(\chi^{2}(1)=0.257, p=0.61\right)$. The most common moderate-severe adverse effects reported were insomnia $(21.4 \%)$, somnolence $(17.9 \%)$, anxiety $(13.6 \%)$, depression $(11.4 \%)$, vomiting $(10.0 \%)$, and headache $(10.0 \%)$; the percentage of participants reporting moderate-severe adverse effects did not differ significantly by condition (all $p s>0.05$ ). Only 1 study participant reported intolerable adverse effects and was advised to cease taking medication.

\section{Drinking Outcomes}

Table 2 shows percent heavy drinking days and average number of drinks per week at each follow-up. Compared to baseline, participants in both conditions showed large and significant reductions in alcohol use at each follow-up ( $p$ s $<0.0001$ using paired $t$-tests). However, the differences between conditions at all time points were minimal. The unadjusted effects sizes for condition differences at each follow-up are shown in Table 2.

GEE analysis of percent heavy drinking days including a priori covariates indicated that the effect of naltrexone versus

Table 1. Baseline Demographic and Clinical Characteristics for the Entire Sample and by Treatment Condition $(N=150)$

\begin{tabular}{|c|c|c|c|}
\hline & $\begin{array}{c}\text { Overall }(N=150) \\
n(\%) \text { or } M(\mathrm{SD})\end{array}$ & $\begin{array}{c}\text { Placebo }(n=75) \\
n(\%) \text { or } M(\mathrm{SD})\end{array}$ & $\begin{array}{c}\text { Naltrexone }(n=75) \\
n(\%) \text { or } M(\mathrm{SD})\end{array}$ \\
\hline Female gender & $62(41.3 \%)$ & $29(38.7 \%)$ & $33(44.0 \%)$ \\
\hline Years of age & $42.1(12.7)$ & $41.8(12.9)$ & $42.3(12.7)$ \\
\hline \multicolumn{4}{|l|}{ Race $^{a}$} \\
\hline White & $109(74.2 \%)$ & $54(74.0 \%)$ & $55(74.3 \%)$ \\
\hline Black/African American & $25(17.0 \%)$ & $12(16.4 \%)$ & $13(17.6 \%)$ \\
\hline Native American & $3(2.0 \%)$ & $3(4.1 \%)$ & $0(0.0 \%)$ \\
\hline Asian & $5(3.4 \%)$ & $3(4.1 \%)$ & $2(2.7 \%)$ \\
\hline Multiple races & $5(3.4 \%)$ & $1(1.4 \%)$ & $4(5.4 \%)$ \\
\hline Hispanic/Latino ${ }^{\mathrm{b}}$ & $9(6.0 \%)$ & $7(9.4 \%)$ & $2(2.7 \%)$ \\
\hline \multicolumn{4}{|l|}{ Education } \\
\hline$<$ High school & $13(8.7 \%)$ & $5(6.7 \%)$ & $8(10.7 \%)$ \\
\hline High school & $40(26.7 \%)$ & $18(24.0 \%)$ & $22(29.3 \%)$ \\
\hline Some college & $60(40.0 \%)$ & $35(46.7 \%)$ & $25(33.3 \%)$ \\
\hline College graduate & $37(24.7 \%)$ & $17(22.7 \%)$ & $20(26.7 \%)$ \\
\hline Unemployed & $57(38.0 \%)$ & $31(41.3 \%)$ & $26(34.5 \%)$ \\
\hline Married or cohabiting & $28(18.7 \%)$ & $15(20.0 \%)$ & $13(17.3 \%)$ \\
\hline \multicolumn{4}{|l|}{ Clinical characteristics } \\
\hline Current alcohol dependence & $42(28.0 \%)$ & $19(25.3 \%)$ & $23(30.7 \%)$ \\
\hline Percent heavy drinking days & $34.0(26.2)$ & $33.9(24.9)$ & $34.2(27.7)$ \\
\hline Drinks per week & $25.2(23.7)$ & $26.5(26.5)$ & $23.9(20.6)$ \\
\hline \multicolumn{4}{|l|}{ Intent to change drinking ${ }^{c}$} \\
\hline No & $7(4.7 \%)$ & $3(4.0 \%)$ & $4(5.3 \%)$ \\
\hline Possibly & $35(23.3 \%)$ & $16(21.3 \%)$ & $19(25.3 \%)$ \\
\hline Probably & $57(38.0 \%)$ & $30(40.0 \%)$ & $27(36.0 \%)$ \\
\hline Definitely & $51(34.0 \%)$ & $26(34.7 \%)$ & $25(33.3 \%)$ \\
\hline Cigarettes smoked per day & $17.4(8.8)$ & $17.9(10.2)$ & $16.9(7.2)$ \\
\hline FTND score & $5.3(2.3)$ & $5.4(2.3)$ & $5.3(2.2)$ \\
\hline
\end{tabular}

FTND, Fagerström Test for Nicotine Dependence.

aThree participants did not answer this question.

${ }^{\mathrm{b}}$ One participant did not answer this question.

${ }^{\mathrm{c}}$ Participants were asked whether they planned to cut down or stop drinking while quitting smoking. 
Table 2. Alcohol Use and Smoking Outcomes by Treatment Condition

\begin{tabular}{|c|c|c|c|}
\hline & $\begin{array}{c}\text { Placebo }(n=75) \\
M(\text { SD })\end{array}$ & $\begin{array}{c}\text { Naltrexone }(n=75) \\
M(\mathrm{SD})\end{array}$ & $\begin{array}{l}\text { Effect size } \\
\quad d\end{array}$ \\
\hline \multicolumn{4}{|l|}{ Treatment exposure } \\
\hline Counseling sessions completed & $3.8(1.6)$ & $3.9(1.6)$ & 0.08 \\
\hline $\begin{array}{l}\text { \% Days using patch: self-report } \\
\% \text { Medication doses taken }\end{array}$ & $74.6(31.1)$ & $78.4(31.2)$ & 0.12 \\
\hline Self-report & $76.8(28.5)$ & $76.3(31.3)$ & -0.02 \\
\hline Pill count & $69.6(27.6)$ & $74.7(30.5)$ & 0.18 \\
\hline Vial openings by MEMS Cap & $55.4(33.1)$ & $61.1(33.2)$ & 0.17 \\
\hline \multicolumn{4}{|l|}{ Drinking outcomes } \\
\hline \multicolumn{4}{|l|}{ Percent heavy drinking days } \\
\hline (Baseline) $(n=150)$ & $33.9(24.9)$ & $34.2(27.7)$ & $\mathrm{N} / \mathrm{A}$ \\
\hline Weeks 1 to 8 after quit date $(n=132)$ & $12.4(19.2)^{f}$ & $15.3(24.6)^{f}$ & $0.04^{\mathrm{a}}$ \\
\hline Weeks 9 to 16 after quit date $(n=132)$ & $18.7(26.1)^{\dagger}$ & $18.7(26.6)^{\dagger}$ & $-0.02^{\mathrm{a}}$ \\
\hline Week 17 to 26 after quit date $(n=131)$ & $16.0(20.8)^{f}$ & $17.0(24.5)^{f}$ & $0.01^{\mathrm{a}}$ \\
\hline \multicolumn{4}{|l|}{ Drinks per week } \\
\hline (Baseline) $(n=150)$ & $26.5(26.5)$ & $23.9(20.6)$ & $\mathrm{N} / \mathrm{A}$ \\
\hline Weeks 1 to 8 after quit date $(n=132)$ & $9.9(10.4)^{f}$ & $10.7(12.0)^{f}$ & $0.02^{\mathrm{a}}$ \\
\hline Weeks 9 to 16 after quit date $(n=132)$ & $11.9(12.3)^{f}$ & $11.8(12.4)^{f}$ & $0.05^{\mathrm{a}}$ \\
\hline Week 17 to 26 after quit date $(n=131)$ & $11.4(11.3)^{f}$ & $11.1(13.1)^{f}$ & $-0.14^{\mathrm{a}}$ \\
\hline Smoking outcomes & $\%$ & $\%$ & $h$ \\
\hline \multicolumn{4}{|l|}{ 7-day point-prevalence abstinence ${ }^{c}$} \\
\hline 2 weeks after quit date & 28.0 & 37.3 & 0.20 \\
\hline 8 weeks after quit date & 22.7 & 20.0 & -0.07 \\
\hline 16 weeks after quit date & 18.7 & 16.0 & -0.07 \\
\hline 26 weeks after quit date & 12.0 & 12.0 & 0.00 \\
\hline Abstinence during treatment ${ }^{\mathrm{c}, \mathrm{d}}$ & 14.7 & 16.0 & 0.04 \\
\hline Continuous smoking abstinence ${ }^{c, e}$ & 8.0 & 5.3 & -0.11 \\
\hline
\end{tabular}

${ }^{a}$ Effect size calculated from log-transformed values due to positive skewness.

${ }^{\text {b }}$ Statistic based on 131 participants who provided complete data regarding whether they lapsed to smoking when drinking alcohol in the 8 weeks after smoking quit date.

${ }^{\mathrm{C}}$ Includes all 150 participants, assuming that only those biochemically confirmed as abstinent were not smoking.

${ }^{d}$ Defined as no smoking from 2 weeks after quit date through the 8-week follow-up.

e Defined as no smoking from 2 weeks after quit date through the 26-week follow-up.

fIndicates significant reduction versus baseline according to paired $t$-tests, all $p s<0.0001$.

placebo was minimal and nonsignificant $(B=-0.04,95 \%$ CI $[-0.30,0.22], p=0.76)$. The naltrexone by time interaction also was nonsignificant $(B=-0.01,95 \%$ CI $[-0.14$, $0.12], p=0.84$ ), indicating that the effect of naltrexone did not differ significantly over time. Higher baseline number of drinks per week was associated with significantly higher percent heavy drinking days $(B=0.30,95 \%$ CI $[0.14,0.45]$, $p=0.0002$ ), and greater baseline intention to reduce drinking during smoking cessation was associated with significantly lower percent heavy drinking days $(B=-0.35,95 \%$ CI $[-0.50,-0.21], p<0.0001)$. In the second step of the model, neither the naltrexone by alcohol dependence $(B=-0.06,95 \%$ CI $[-0.60,0.48], p=0.83)$ nor the naltrexone by female gender $(B=0.27,95 \%$ CI $[-0.30,0.84]$, $p=0.35)$ interactions were significant.

The main effect of naltrexone on number of drinks per week was nonsignificant $(B=-0.09,95 \%$ CI $[-0.35,0.18]$, $p=0.54)$, as was the naltrexone by time interaction $(B=-0.08,95 \%$ CI $[-0.20,0.05], p=0.23)$. Interactions between naltrexone and both alcohol dependence and gender were nonsignificant, $p s>0.60$. Effect sizes for naltrexone for percent heavy drinking days and drinks per week remained similar when analyses were restricted to those with high medication adherence: $B=-0.09,95 \%$ CI $[-0.41,0.24]$ and $B=-0.13,95 \%$ CI [ $-0.48,0.22]$, respectively.

Exploratory analyses of drinking outcomes in the 2 weeks prior to target quit smoking date, as well as analyses of drinks per drinking day as an outcome variable, did not indicate any advantage of naltrexone over placebo. Finally, we ran a model including abstinence from smoking at the time of alcohol assessment to determine whether smoking outcomes were associated with drinking outcomes. The timevarying effect of smoking abstinence on percent heavy drinking days $(B=-0.06,95 \%$ CI $[-0.26,0.15], p=0.58)$ and drinks per week $(B=-0.03,95 \%$ CI $[-0.22,0.16], p=0.77)$ was nonsignificant.

\section{Smoking Outcomes}

Overall, 131 participants provided daily data on smoking during treatment (weeks 1 to 8 after quit date), of whom 99 reported a smoking lapse. Of these lapses, 34 (34.3\%) occurred when participants were drinking (see Table 2). Multiple logistic regression analyses indicated that although 
the effect of naltrexone on reducing the odds of having an alcohol-involved lapse to smoking was in the hypothesized direction, it was nonsignificant, odds ratio $(\mathrm{OR})=0.51$, $95 \%$ CI $[0.22,1.14], p=0.10$.

The percent of all participants in each condition who were biochemically confirmed abstinent from smoking at 2, 8, 16, and 26 weeks is shown in Table 2. GEE analyses including a priori covariates indicated that the effect of naltrexone versus placebo on smoking abstinence was minimal, contrary to the hypothesized direction of effect, and nonsignificant, $\mathrm{OR}=0.93,95 \% \mathrm{CI}[0.46,1.86], p=0.83$. The naltrexone by time interaction also was nonsignificant $(\mathrm{OR}=0.82,95 \% \mathrm{CI}$ $[0.61,1.11], p=0.20)$. No baseline covariates were significantly associated with smoking abstinence. Neither the naltrexone by alcohol dependence $(\mathrm{OR}=1.17,95 \%$ CI $[0.27$, 5.06], $p=0.83$ ) nor the naltrexone by female gender $(\mathrm{OR}=0.55,95 \% \mathrm{CI}[0.15,1.99], p=0.36)$ interactions were significant. Analyses restricted to those with high medication adherence also yielded an effect for naltrexone in the opposite direction hypothesized: $\mathrm{OR}=0.61,95 \%$ CI $[0.26,1.42]$. Logistic regression analysis of the odds of continuous smoking abstinence during active treatment $(\mathrm{OR}=1.09,95 \% \mathrm{CI}$ $[0.44,2.71], p=0.85)$ and across 26 weeks $(\mathrm{OR}=0.62,95 \%$ CI $[0.15,2.29], p=0.48)$ indicated that the effect of naltrexone was nonsignificant.

\section{DISCUSSION}

Our study provided no evidence that naltrexone compared to placebo reduced alcohol use or enhanced smoking cessation outcomes in heavy drinkers seeking smoking cessation treatment. It is important to note that we were not able to achieve our desired sample size, thereby resulting in lessthan-desired statistical power. However, the effect sizes observed for naltrexone were well below the effect size on which we powered the trial, suggesting that any effects of naltrexone likely would have been minimal. These results are inconsistent with 2 post hoc analyses of smaller subsamples of heavy drinkers in smoking cessation trials, which found naltrexone reduced alcohol use (O'Malley et al., 2009; $n=102$; Fridberg et al., 2014; $n=69)$ and enhanced smoking cessation (Fridberg et al., 2014).

The negative findings of this trial, compared to the aforementioned trials, may have resulted from a few key design features. First, our study included counseling that explicitly addressed alcohol use within smoking cessation counseling; a version of this counseling has been shown to reduce drinking by about $40 \%$ (Kahler et al., 2008). In contrast, studies by Fridberg and colleagues (2014) and O'Malley and colleagues (2009) did not focus on drinking. Second, as part of counseling, all participants were informed that naltrexone might help them reduce drinking and thereby facilitate smoking cessation. Placebo effects in alcohol trials are robust and associated with reduced treatment effect size (Litten et al., 2013). In the present study, percent heavy drinking days and average drinks per week reduced by about $50 \%$ in the placebo condition; in Fridberg and colleagues (2014), drinking was relatively unchanged in those receiving placebo, and in O'Malley and colleagues (2009), 85\% of those receiving placebo continued to drink heavily. Thus, a combination of factors in the current study may have led to reductions in drinking across all participants that were sufficiently large to obscure naltrexone effects. Finally, studies that have established the efficacy of naltrexone for reducing alcohol consumption (Jonas et al., 2014) have typically been conducted in very heavy drinking individuals, who may have more room for showing improvements in drinking compared to those in the present study. However, participants in this study drank substantially more heavily at baseline compared to the Fridberg and colleagues (2014) and O'Malley and colleagues (2009) heavy-drinking subsamples; therefore, it is unclear whether the level of drinking in this sample accounts for the negative findings.

An alternative hypothesis for the negative results of the present trial is that naltrexone concentrations achieved may not have been sufficient to lead to adequate blockade of brain mu opioid receptors, presumed to be a primary mechanism of action for naltrexone. Adherence to naltrexone was modest (55 to $78 \%$ of possible doses taken), and we did not have biochemical assessment of naltrexone metabolites. In the Fridberg and colleagues (2014) and O'Malley and colleagues (2009) trials, adherence was estimated at 75 to $78 \%$. Given that higher naltrexone adherence is associated with better outcomes (Swift et al., 2011), we cannot exclude the possibility that a naltrexone effect would have been detected had medication adherence been higher. However, we found no evidence of higher effect sizes for naltrexone among those with relatively high oral medication adherence. Finally, although results of the O'Malley and colleagues (2009) doseranging study tended to support a 25 or $50 \mathrm{mg}$ naltrexone dose, it is possible that a $100 \mathrm{mg}$ dose may have had a stronger effect in the present sample given higher levels of drinking and alcohol dependence.

Smoking cessation rates in the present study were low. These low rates may reflect the nature of the sample recruited, which was characterized by low education, high rates of unemployment, and heavy drinking, known risk factors for poor smoking cessation outcomes. They also could reflect the short duration of nicotine replacement therapy used (i.e., 6 weeks vs. 10+ weeks), although an association between longer nicotine replacement therapy and better smoking outcome has not been demonstrated (Stead et al., 2012). Although more intensive counseling may have increased smoking cessation rates, there is not clear evidence that increasing intensity of behavioral interventions combined with pharmacotherapy increases quit rates (Stead et al., 2016). Given that the primary benefit of naltrexone on smoking cessation was expected to be due to its effects on drinking, the lack of an effect of naltrexone on smoking cessation was not surprising and adds further to the literature indicating that naltrexone is not an efficacious smoking cessation pharmacotherapy (Hartmann-Boyce et al., 2014). The 
only indication of potential benefit of naltrexone, which was not statistically significant, was in the 2 weeks immediately after the target quit smoking date. Kappa opioid receptors (KORs) have been implicated in nicotine withdrawal (Jackson et al., 2015), and it is possible that naltrexone has some limited benefit to smoking cessation in the early phases of smoking cessation by antagonizing KORs.

We examined 2 potential moderators of naltrexone's efficacy, alcohol dependence, and gender. Current alcohol dependence was not significantly associated with drinking or smoking outcomes and did not interact significantly with naltrexone. Thus, in the context of smoking cessation counseling that includes a substantial focus on reducing drinking, smokers with alcohol dependence appear capable of making meaningful reductions in drinking and achieving similar smoking outcomes to heavy drinkers without alcohol dependence. Gender also did not significantly moderate naltrexone effects on drinking or smoking outcomes; future studies examining gender differences, however, should collect data on menstrual cycle which may influence naltrexone response (Roche and King, 2015). Future studies could examine other potential moderators of naltrexone response such as family history of alcohol dependence and polymorphisms in opioid receptor genes (Garbutt et al., 2014).

\section{Strengths and Limitations}

This study featured rigorous experimental control, a broad community recruitment strategy, and inclusion of smokers with and without alcohol dependence. However, it had modest statistical power due to under-enrollment of participants. Low enrollment may have resulted from numerous factors: (i) even with targeted recruitment, less than one-third of potential participants met study inclusion criteria and only half of those continued through baseline enrollment; (ii) the smoking rate in Rhode Island-with a population of just over 1 million-has fallen substantially; and (iii) effective smoking cessation pharmacotherapy is widely available to smokers, making study participation less attractive. Our experience suggests the need for conducting smoking cessation research on high-risk subpopulations within larger population centers, in multisite trials, or within existing smoking cessation programs.

The study did not have biochemical verification of naltrexone compliance or alcohol use. Only 1 dose of naltrexone was tested. The relatively low threshold for heavy drinking in study inclusion criteria and the fact that a substantial portion of the sample had low interest in changing drinking may have further reduced the potential impact of naltrexone.

\section{CONCLUSIONS}

This study had low power to detect the effect sizes for naltrexone typically seen in clinical trials, and participants were only moderately adherent to study medication. Nonetheless, with a sample of 150 participants, the effect sizes and confidence intervals obtained provided no evidence that naltrexone provides benefit when given to heavy drinking smokers who quit smoking while also receiving nicotine patch and counseling to addresses both alcohol use and smoking cessation. Results do suggest, however, that heavy drinkers, including those with current alcohol dependence, can make substantial reductions in drinking when they try to quit smoking and receive multiple sessions of counseling that explicitly addresses heavy drinking. Furthermore, the present results and those in previous trials using in-person counseling (Kahler et al., 2008; O'Malley et al., 2009) indicate that changes in drinking are relatively independent of smoking cessation success. Thus, the context of smoking cessation treatment offers an ideal opportunity in which to effect changes in individuals who drink heavily; changes in drinking may be sustained even in the likely case of failure to maintain long-term smoking abstinence. However, the potential value of alcohol pharmacotherapies in smoking cessation treatment when used in combination with differing levels of behavioral alcohol intervention requires further study.

\section{FUNDING}

This research was supported by grant R01 AA017181 from the National Institute on Alcohol Abuse and Alcoholism to CWK. The content of this article is solely the responsibility of the authors and does not necessarily represent the official views of the National Institutes of Health.

\section{FINANCIAL DISCLOSURES}

Dr. O'Malley is a member of the American Society of Clinical Psychopharmacology Workgroup supported by Arbor Pharma, Indivior, Ethypharm, Eli Lilly, Lundbeck, Otsuka, Pfizer, and Arbor Pharmaceuticals. She has served as a consultant for Alkermes, Amygdala, Cerecor, and Opiant, on the Scientific Review Group for Hazelden Betty Ford Foundation, and received study medications from Pfizer and Astra Zeneca. All other authors have no potential conflict of interests to disclose.

\section{REFERENCES}

American Psychiatric Association (1994) Diagnostic and Statistical Manual of Mental Disorders, 4th edn. American Psychiatric Association, Washington, DC.

Augustson EM, Wanke KL, Rogers S, Bergen AW, Chatterjee N, Synder K, Albanes D, Taylor PR, Caporaso NE (2008) Predictors of sustained smoking cessation: a prospective analysis of chronic smokers from the alphatocopherol beta-carotene cancer prevention study. Am J Public Health 98:549-555.

Baer JS, Lichtenstein E (1988) Classification and prediction of smoking relapse episodes: an exploration of individual differences. J Consult Clin Psychol 56:104-110.

Borland R (1990) Slip-ups and relapse in attempts to quit smoking. Addict Behav 15:235-245. 
Brown RA, Abrantes AM, Strong DR, Niaura R, Kahler CW, Miller IW, Price LH (2014) Efficacy of sequential use of fluoxetine for smoking cessation in elevated depressive symptom smokers. Nicotine Tob Res 16:197207.

Brown RA, Burgess ES, Sales SD, Whiteley JA, Evans DM, Miller IW (1998) Reliability and validity of a smoking timeline follow-back interview. Psychol Addict Behav 12:101-112.

Cook JW, Fucito LM, Piasecki TM, Piper ME, Schlam TR, Berg KM, Baker TB (2012) Relations of alcohol consumption with smoking cessation milestones and tobacco dependence. J Consult Clin Psychol 80:1075-1085.

Cropsey KL, Trent LR, Clark CB, Stevens EN, Lahti AC, Hendricks PS (2014) How low should you go? Determining the optimal cutoff for exhaled carbon monoxide to confirm smoking abstinence when using cotinine as reference. Nicotine Tob Res 16:1348-1355.

Dollar KM, Homish GG, Kozlowski LT, Leonard KE (2009) Spousal and alcohol-related predictors of smoking cessation: a longitudinal study in a community sample of married couples. Am J Public Health 99:231233.

Ebbert JO, Janney CA, Sellers TA, Folsom AR, Cerhan JR (2005) The association of alcohol consumption with coronary heart disease mortality and cancer incidence varies by smoking history. J Gen Intern Med 20:14-20.

Epperson CN, Toll B, Wu R, Amin Z, Czarkowski KA, Jatlow P, Mazure CM, O'Malley SS (2010) Exploring the impact of gender and reproductive status on outcomes in a randomized clinical trial of naltrexone augmentation of nicotine patch. Drug Alcohol Depend 112:1-8.

Epstein AM, King AC (2004) Naltrexone attenuates acute cigarette smoking behavior. Pharmacol Biochem Behav 77:29-37.

Fiore MC, Jaén C, Baker TB, Bailey WC, Benowitz NL, Curry SJ, Dorfman SF (2008) Treating Tobacco Use and Dependence: 2008 Update. U.S. Department of Health and Human Services, Public Health Service, Rockville, MD.

First MB, Spitzer RL, Gibbon M, Williams JBW (1995) Structured Clinical Interview for DSM-IV Axis I Disorders. New York State Psychiatric Institute, New York, NY.

Fridberg DJ, Cao D, Grant JE, King AC (2014) Naltrexone improves quit rates, attenuates smoking urge, and reduces alcohol use in heavy drinking smokers attempting to quit smoking. Alcohol Clin Exp Res 38:2622-2629.

Garbutt JC, Greenblatt AM, West SL, Morgan LC, Kampov-Polevoy A, Jordan HS, Bobashev GV (2014) Clinical and biological moderators of response to naltrexone in alcohol dependence: a systematic review of the evidence. Addiction 109:1274-1284.

Gossop M, Keaney F, Stewart D, Marshall EJ, Strang J (2002) A Short Alcohol Withdrawal Scale (SAWS): development and psychometric properties. Addict Biol 7:37-43.

Hartmann-Boyce J, Stead LF, Cahill K, Lancaster T (2014) Efficacy of interventions to combat tobacco addiction: Cochrane update of 2013 reviews. Addiction 109:1414-1425.

Heatherton TF, Kozlowski LT, Frecker RC, Fagerström KO (1991) The Fagerström test for nicotine dependence: a revision of the Fagerstrom Tolerance Questionnaire. Br J Addict 86:1119-1127.

Hughes JR, Keely JP, Niaura RS, Ossip-Klein DJ, Richmond RL, Swan GE (2003) Measures of abstinence in clinical trials: issues and recommendations. Nicotine Tob Res 5:13-25.

Humfleet G, Munoz R, Sees K, Reus V, Hall S (1999) History of alcohol or drug problems, current use of alcohol or marijuana, and success in quitting smoking. Addict Behav 24:149-154.

Jackson KJ, Jackson A, Carroll FI, Damaj MI (2015) Effects of orally-bioavailable short-acting kappa opioid receptor-selective antagonist LY2456302 on nicotine withdrawal in mice. Neuropharmacology 97:270274.

Jonas DE, Amick HR, Feltner C, Bobashev G, Thomas K, Wines R, Kim MM, Shanahan E, Gass CE, Rowe CJ, Garbutt JC (2014) Pharmacotherapy for adults with alcohol use disorders in outpatient settings a systematic review and meta-analysis. JAMA 311:1889-1900.

Kahler CW, Borland R, Hyland A, McKee SA, Thompson ME, Cummings KM (2009) Alcohol consumption and quitting smoking in the
International Tobacco Control (ITC) Four Country Survey. Drug Alcohol Depend 100:214-220.

Kahler CW, Metrik J, Lachance HR, Ramsey SE, Abrams DB, Monti PM, Brown RA (2008) Addressing heavy drinking in smoking cessation treatment: a randomized clinical trial. J Consult Clin Psychol 76:852-862.

Kahler CW, Spillane NS, Metrik J (2010) Alcohol use and initial smoking lapses among heavy drinkers in smoking cessation treatment. Nicotine Tob Res 12:781-785.

King AC, Cao D, O'Malley SS, Kranzler HR, Cai X, Dewit H, Matthews AK, Stachoviak RJ (2012) Effects of naltrexone on smoking cessation outcomes and weight gain in nicotine-dependent men and women. J Clin Psychopharmacol 32:630-636.

King AC, Meyer PJ (2000) Naltrexone alteration of acute smoking response in nicotine-dependent subjects. Pharmacol Biochem Behav 66:563-572.

Kranzler HR, Armeli S, Tennen H, Blomqvist O, Oncken C, Petry N, Feinn R (2003) Targeted naltrexone for early problem drinkers. J Clin Psychopharmacol 23:294-304.

Leeman RF, McKee SA, Toll BA, Krishnan-Sarin S, Cooney JL, Makuch RW, O'Malley SS (2008) Risk factors for treatment failure in smokers: relationship to alcohol use and to lifetime history of an alcohol use disorder. Nicotine Tob Res 10:1793-1809.

Levine J, Schooler NR (1986) SAFTEE: a technique for the systematic assessment of side effects in clinical trials. Psychopharmacol Bull 22:343381.

Litten RZ, Castle IJ, Falk D, Ryan M, Fertig J, Chen CM, Yi HY (2013) The placebo effect in clinical trials for alcohol dependence: an exploratory analysis of 51 naltrexone and acamprosate studies. Alcohol Clin Exp Res 37:2128-2137.

McKee SA, Falba T, O’Malley SS, Sindelar J, O'Connor PG (2007) Smoking status as a clinical indicator for alcohol misuse in US adults. Arch Intern Med 167:716-721.

Meyerhoff DJ, Tizabi Y, Staley JK, Durazzo TC, Glass JM, Nixon SJ (2006) Smoking comorbidity in alcoholism: neurobiological and neurocognitive consequences. Alcohol Clin Exp Res 30:253-264.

Miller W, Rollnick S (2012) Motivational Interviewing: Helping People Change. The Guildford Press, New York, NY.

Mooney ME, Schmitz JM, Allen S, Grabowski J, Pentel P, Oliver A, Hatsukami DK (2016) Bupropion and naltrexone for smoking cessation: a double-blind randomized placebo-controlled clinical trial. Clin Pharmacol Ther 100:344-352.

Morgenstern J, Kuerbis AN, Chen AC, Kahler CW, Bux DA JR, Kranzler HR (2012) A randomized clinical trial of naltrexone and behavioral therapy for problem drinking men who have sex with men. J Consult Clin Psychol 80:863-875.

Murray RP, Istvan JA, Voelker HT, Rigdon MA, Wallace MD (1995) Level of involvement with alcohol and success at smoking cessation in the lung health study. J Stud Alcohol 56:74-82.

O'Malley SS, Corbin WR, Leeman RF, Demartini KS, Fucito LM, Ikomi J, Romano DM, Wu R, Toll BA, Sher KJ, Gueorguieva R, Kranzler HR (2015) Reduction of alcohol drinking in young adults by naltrexone: a double-blind, placebo-controlled, randomized clinical trial of efficacy and safety. J Clin Psychiatry 76:e207-e213.

O'Malley SS, Krishnan-Sarin S, McKee SA, Leeman RF, Cooney NL, Meandzija B, Wu R, Makuch RW (2009) Dose-dependent reduction of hazardous alcohol use in a placebo-controlled trial of naltrexone for smoking cessation. Int J Neuropsychopharmacol 12:589-597.

Pettinati HM, Weiss RD, Miller WR, Donovan D, Ernst DB, Rounsaville BJ (2004) RE: COMBINE Monograph Series, Volume 2. Medical Management Treatment Manual: A Clinical Research Guide for Medically Trained Clinicians Providing Pharmacotherapy as Part of the Treatment for Alcohol Dependence. DHHS Publication No (NIH)04-5289, Bethesda, MD.

Ray LA, Miranda R Jr, Kahler CW, Leventhal AM, Monti PM, Swift R, Hutchison KE (2007) Pharmacological effects of naltrexone and intravenous alcohol on craving for cigarettes among light smokers: a pilot study. Psychopharmacology 193:449-456. 
Roche DJ, King AC (2015) Sex differences in acute hormonal and subjective response to naltrexone: the impact of menstrual cycle phase. Psychoneuroendocrinology 52:59-71.

Rohsenow DJ, Monti PM, Hutchison KE, Swift RM, Mackinnon SV, Sirota AD, Kaplan GB (2007) High-dose transdermal nicotine and naltrexone: effects on nicotine withdrawal, urges, smoking, and effects of smoking. Exp Clin Psychopharmacol 15:81-92.

Rukstalis M, Jepson C, Strasser A, Lynch KG, Perkins K, Patterson F, Lerman $C$ (2005) Naltrexone reduces the relative reinforcing value of nicotine in a cigarette smoking choice paradigm. Psychopharmacology 180:41-48.

SAS Institute Inc (2012) SAS 9.4. for Windows [Computer software], SAS, Cary, NC.

Schroder H, Marrugat J, Elosua R, Covas MI (2002) Tobacco and alcohol consumption: impact on other cardiovascular and cancer risk factors in a southern European Mediterranean population. Br J Nutr 88:273-281.

Shiffman S, Paty JA, Gnys M, Kassel JA, Hickcos M (1996) First lapses to smoking: within-subjects analysis of real-time reports. J Consult Clin Psychol 64:366-379.

Smith PM, Kraemer HC, Miller NH, Debusk RF, Taylor CB (1999) In-hospital smoking cessation programs: Who responds, who doesn't? J Consult Clin Psychol 67:19-27.

Sobell LC, Sobell MB (1996) Timeline Followback: A Calendar Method for Assessing Alcohol and Drug Use. Addiction Research Foundation, Toronto, ON, Canada.

SRNT Subcommittee on Biochemical Verification (2002) Biochemical verification of tobacco use and cessation. Nicotine Tob Res 4:149-159.

Stead LF, Koilpillai P, Fanshawe TR, Lancaster T (2016) Combined pharmacotherapy and behavioural interventions for smoking cessation. Cochrane Database Syst Rev (3):CD008286.
Stead LF, Perera R, Bullen C, Mant D, Hartmann-Boyce J, Cahill K, Lancaster T (2012) Nicotine replacement therapy for smoking cessation. Cochrane Database Syst Rev (11):CD000146.

Sullivan JT, Sykora K, Schneiderman J, Naranjo CA, Sellers EM (1989) Assessment of alcohol withdrawal: the revised clinical institute withdrawal assessment for alcohol scale (CIWA-Ar). Br J Addict 84:13531357.

Sutherland G, Stapleton JA, Russell MA, Feyerabend C (1995) Naltrexone, smoking behaviour and cigarette withdrawal. Psychopharmacology $120: 418-425$.

Swift R, Oslin DW, Alexander M, Forman R (2011) Adherence monitoring in naltrexone pharmacotherapy trials: a systematic review. J Stud Alcohol Drugs 72:1012-1018.

Toll BA, Cummings KM, O'Malley SS, Carlin-Menter S, McKee SA, Hyland A, Wu R, Hopkins J, Celestino P (2012) Tobacco quitlines need to assess and intervene with callers' hazardous drinking. Alcohol Clin Exp Res 36:1653-1658.

Toll BA, Martino S, O’Malley SS, Fucito LM, McKee SA, Kahler CW, Rojewski AM, Mahoney MC, Wu R, Celestino P, Seshadri S, Koutsky J, Hyland A, Cummings KM (2015) A randomized trial for hazardous drinking and smoking cessation for callers to a quitline. J Consult Clin Psychol 83:445-454.

Wei I (1978) Application of an urn model to the design of sequential controlled clinical trials. J Am Stat Assoc 73:559-563.

Yardley MM, Mirbaba MM, Ray LA (2015) Pharmacological options for smoking cessation in heavy-drinking smokers. CNS Drugs 29:833-845.

Zeger SL, Liang K-Y (1986) Longitudinal data analysis for discrete and continuous outcomes. Biometrics 42:121-130. 